\title{
'We have experienced a tragedy which words cannot properly describe': Representations of Trauma in Post-9/11 Superhero Comics
}

\author{
Philip Smith ${ }^{1}$ and Michael Goodrum ${ }^{2} * *$ \\ ${ }^{1}$ Loughborough University \\ ${ }^{2}$ University of Essex
}

\section{Abstract}

This paper explores the manifestation of trauma in superhero comics following the terrorist attacks on the World Trade Center on September 11. These texts are considered from the perspectives of clinical psychology and Silverman's concept of historical trauma. The paper first examines the genre as a whole, followed by an exploration of elements common to the genre as exemplified in the Avengers: Disassembled plot arc.

The terrorist attacks on the World Trade Center on 11 September 2001 were represented as a moment of historical rupture. Nowhere was this more clearly stated than in Charles Krupa's statement in Time on 12 September 2001 that 'morning came, and everything was changed' (Krupa 1). Notions of rupture had an impact on collective perceptions of the future as a logical progression from the present (Neal 7). In short, the trauma of the attacks disrupted narratives that ordered US society and the experience of those within it. Kaja Silverman has characterised these narratives as the 'dominant fiction', the "images and stories through which a society figures consensus" (30) and maintains a particular set of power relations that work towards naturalising connections between men and power. In Silverman's terms, then, any disruption to the dominant fiction poses a threat to the "commensurability of penis and phallus" (42) and as a result the entire social order can be called into question as ideological belief in ordering narratives wanes. Silverman labels this destabilising force as 'historical trauma'.

There are means of resisting the impact of historical trauma, however. Most notably, events can be inserted into a coherent narrative that reduces their ability to destabilise ongoing projects of order. In this respect, 9/11 was positioned by the US media as the opening shot in a War on Terror that would ultimately bring those behind the attacks to justice. Attempts to contain instances of historical trauma through placing them in narratives engages with the micro-scale therapeutic work of clinical psychologists. In the project of 'finding meaning' or 'redefining the event', therapy seeks to realign the traumatised individual with existing ideological structures; on a cultural level, attempts to contain moments of historical trauma seek to validate those ideological structures and ensure the continued investment of belief on which they depend.

This paper will focus on mainstream superhero comics and (in one case) comics which employ the conventions of that genre under another guise, offering a sketch of the key texts in the post-9/11 world and the process of, to employ Weber's term 'rephallusization' (53), of restoring former positions of masculine order. Specifically, the paper considers the representation of the events of $9 / 11$ as a healing process, the 'dephallusization', or loss of faith in superheroes in terms of US mythology. The latter half of the paper consid- 
ers the redefining of superheroes in order to return hegemonic masculinity to a position of power in an alternative guise, and the construction of the terrorist along lines of gender and nationality. It is beyond the scope of this essay to consider representations of trauma in prose, fiction, post-9/11 superhero films or in alternative comics (all of which offer potentially rich readings). Such specificity of scope is necessary when considering post-9/11 fiction. There was no one response to the attacks and the range of responses, both in terms of media and emotional content expressed, are too varied to be spoken of as a whole. The texts considered in this paper represent only those from a specific genre with commonly recurring motifs and sentiments. The approach of this paper will be informed by two models of trauma, both of which have already been mentioned: that offered by clinical psychology and Silverman's concept of historical trauma. Tensions between these perspectives will also be explored.

\section{Re-enactment}

In the terms of clinical psychology, trauma occurs when an individual is faced with an event beyond comprehension that resists integration into their existing understanding of the world. The disruptive effects of trauma manifest themselves through misperceptions of personal threat, through nightmares and flashbacks. Through treatment, the traumatised individual can, in some cases, be restored to mental health and learn to exercise control over these traumatic symptoms. One approach that works towards this result is the project of 'redefining the event', which involves narrating the traumatic moment (Kraft 1). On this topic, Goleman contends that:

As patients retell the horrific details of the trauma, the memory starts to be transformed, both in its emotional meaning and in its effects on the emotional brain. The pace of this retelling is delicate; ideally it mimics the pace that occurs naturally in those people who are able to recover from trauma without suffering PTSD. In these cases, there often seems to be an inner clock that "doses" people with intrusive memories that relive the trauma, intercut with weeks or months when they remember hardly anything of the horrible events. (211)

Whilst trauma "exceeds the possibility of narrative knowledge," (79) the trauma narrative is an attempt to render that which is beyond comprehension, and even articulation, in more familiar terms. In so doing, the power exercised over the patient by the traumatic experience is diminished and the patient is realigned with existing ideological structures. The 9/11 attacks, Dori Laub contends, were 'a story in search of a voice' (214). Fiction became a means to give a voice to that story, a way of speaking the unspeakable. Richard Gray contends that "perhaps one way to tell a story that cannot be told is to tell it aslant, to approach it by stealth" (34). By telling a story with a different location, happening to different people and with different outcomes (essentially, by telling a different story) an event can be stripped of its immediacy and horror whilst maintaining a certain kernel of truth which could not otherwise be told. In the case of mainstream superhero comic books, the re-enactment of the unspeakable is transformed in a manner which recognises not only the events of the attacks, but the emotional impact of trauma that followed.

Re-enactment as a healing process is visible in mainstream superhero comics. Not only are the events retold and rendered into a familiar framework but they are changed in a manner which radically redefines the event. The 'stealth' approach becomes, not simply a way through which the event can be approached, but a way in which it can be altered and retold with a different meaning. Secret Invasion establishes direct links to $9 / 11$ through restaging the moments when the planes crashed into the World Trade Center. Published 
by Marvel from 2008 to 2009, Secret Invasion was a crossover arc that was repeatedly drawn back to images of attacks on towers. ${ }^{1}$ In this arc, an alien race known as Skrulls attack Earth; motivated by religious extremism, the Skrulls believe Earth to be their sacred home and therefore embark on a crusade to claim it. With the ability to disguise themselves seamlessly the Skrulls, like the terrorists described in President Bush's State of the Union Address, 'spread throughout the world like ticking time bombs, set to go off without warning' (Bush 1). As one would expect of a bomb, these particular 'time bombs' cause a great deal of damage and confusion when they 'detonate'. Like their real world counterparts, however, causing damage is the sole extent of their success. In some cases, even the level of damage is minimal.

At one point in the narrative a Skrull craft hits a tower but causes no serious damage, merely catching the tower a glancing blow before crashing to the ground; the crew, however, fall to their deaths. The terrorist attacks of September 11 are therefore restaged with a markedly different outcome: the tower and its inhabitants are safe but the attackers fall to their death, inverting the images of people jumping from the World Trade Center. The outcome of terrorist attacks in Secret Invasion may be so different due to the fact that the X-Men, the superheroes defending the tower, are prepared for their enemy. A crucial element in avoiding the effects of trauma, preparedness enables the X-Men to escape unscathed whilst the Skrulls are wiped out. The suggestion being that surprise, rather than an inherent weakness in US military power, allowed the attacks to take place. A prepared US would not suffer the same tragedy again. Only the attackers die, whilst the tower representative of phallic power proves impervious to attack. Such phallic power also shields the inhabitants of the towers, cocooning them inside a symbol of masculine supremacy and providing reassuring messages to the audience about the ability of masculine power to shield the nation from further attacks.

In Avengers: Disassembled, as with 9/11, it takes time for narratives to emerge from devastation. The plot hinges on the mental breakdown of Wanda Maximoff, the Avenger and former mutant terrorist, known as the Scarlet Witch but this does not become apparent until almost the end of the arc. Although there are exceptions, superhero narrative conventions generally dictate that the respective roles of heroes and villains will be clear cut - ambiguity would call into question the use of extra-legal violence as a means of maintaining order. Instead of this straightforward approach, Avengers: Disassembled is characterised by confusion and disorientation, an experience emotionally similar to the day of the attacks and yet, crucially, contained in a familiar medium. This state of confusion is reinforced through the widespread presence of hallucinations, flashbacks and repetition throughout the text.

In a further indication of trauma, Avengers: Disassembled repeatedly returns the reader to the terrorist attacks of September 2001. Jack of Hearts effectively suicide bombs Avengers Mansion; the Vision then crashes a plane into what remains of the building; Captain America is frequently returned to the moment of Bucky's death. Like 9/11, the attack is doubled and the delayed nature of the second attack on a culturally significant building (reinforcing notions of national identity and insider/outsider distinctions) ensures that scenes of spectacular disorder are captured live on camera and transmitted to the widest possible audience. The trauma of the Avengers is therefore experienced vicariously by a potential global audience. Imagery is not the only way in which Avengers: Disassembled engages with $9 / 11$. The language of the arc also recalls both $9 / 11$ and the ongoing War on Terror through frequent use of the words 'terrorist' and 'terrorism'. 2

Avengers: Disassembled also makes more indirect references to $9 / 11$. One of the narratives that feeds into the arc takes place not on Earth but in Asgard, the realm of the Norse 
gods. Between August and December 2004, Thor dealt with Ragnarok, the final battle that heralds the death and subsequent rebirth of the world in Norse mythology. Connections are therefore established to the idea of $9 / 11$ as a new beginning, a moment of historical rupture that cannot be assimilated into what has gone before. The concept of Ragnarok makes present the sacrifices inherent in such new beginnings, though, as it emphasises death as the price of rebirth. 9/11 is also recalled through the fact that Loki, Thor's half-brother and god of mischief, heralds the beginning of Ragnarok through discovering the mold used to forge Mjolnir, the hammer wielded by Thor that acts as a conduit for his power. Loki then uses this mold to forge weapons for his army, producing hammers only slightly less powerful than Mjolnir. The technology of agencies of order is therefore turned against them, just as planes were used as weapons in the 9/11 attacks.

The insertion of superheroes into the story of the September 11 terrorist attacks allows an element of control to be integrated into the narrative. In terms of clinical psychology, a sense of control is key in preventing trauma. Goleman contends that:

Helplessness as the wild card in triggering PTSD has been shown in dozens of studies on pairs of laboratory rats, each in a different cage, each being given mild - but, to a rat, very stressful, electric shocks of identical severity. Only one rat has a lever in its cage; when the rat pushes the lever, the shock stops for both cages. Over days and weeks, both the rats get precisely the same amount of shock. But the rat with the power to turn the shocks off comes through without lasting signs of stress. (204)

Superheroes can confront their enemies and exercise powers unavailable to normal people. By reliving the attacks through superheroes, a new narrative of the attacks becomes available, one with the crucial element of control inserted.

Attempts are also made to disavow the impact of $9 / 11$ even as its impact is being writ large across the narrative. In The Invincible Iron Man \#88, a reporter witnesses Tony Stark falling from the sky, restaging the image of the 'falling man' jumping from the burning World Trade Center. Unlike the victims of $9 / 11$, however, Stark is protected by his Iron Man armour and as a result he lands without coming to any harm. The superhero genre allows the attacks to be contained within the familiar and its outcomes are evoked but resolved without any adverse effects. Life may not be the same as it was prior to the exposure to historical trauma but Stark's armour and the superhuman rules it follows inject an element of control into the narrative, a means of, quite literally, avoiding the impact of trauma.

As with the Secret Invasion narrative, and many other superhero comics which followed 9/11, miscellaneous images haunt the text and attest to the impact of trauma. Although not remarkable for the genre, Captain America being buried under rubble in Captain America \#32 takes on a new resonance following the collapse of the World Trade Center and subsequent rescue attempts. Likewise, Stark holding the body of his dead girlfriend in The Invincible Iron Man \#87 makes grief directly present in the narrative. Whilst the events of 9/11 do not have a monopoly over grief or urban destruction, such imagery pre-dated the attacks in the mainstream superhero comic genre by some time, after the attacks, these elements took on a symbolic weight they did not have before. Ulrich Baer comments on the pervasiveness of 9/11 imagery that "[e]ach plastic knife [now] made us feel, wrongly, improperly, brashly, that our imagination had failed us before September 11; who would have thought that butter knives could be ominous?' (Baer 8) The meaning of previously innocuous objects and imagery changed. After the 9/11 attacks, these elements came to signify something far more terrible than before. 
Gray contends that to employ traditional narrative structures and dramatic devices in post-9/11 fiction is to 'assimilate the unfamiliar into familiar structures. The crisis is, in every sense of the word, domesticated' (30). In many of the works of fiction discussed by Gray, the process of domestication is marked by tensions and unease, where the familiar becomes paradoxically uncomfortable and inappropriate in the wake of trauma. The same process is notable in superhero comics for its jarring ease of assimilation. In a fictional world where large-scale urban destruction is commonplace, the 9/11 attacks are unfamiliar only in that they are a genuine, rather than fictional, event. And yet, because the destruction of a cityscape is such a common event in a superhero comic, the genre itself must now bear the weight of what it means for a city to truly come under attack. The once innocent and familiar sign of cartoonish destruction means something else. To withdraw it would be to call attention to it and yet to return to it now signals something horrific. In Silverman's terms, the dominant fiction is exposed precisely as fictional - as a system of interlocking ideologies that promote a particular social hierarchy - and it therefore loses the 'natural' appearance so essential to the continued investment of ideological belief. We shall now consider the texts in these terms.

\section{9/11 and Masculine Power Under Threat}

In terms of clinical psychology, familiarisation through re-enactment of the traumatic moment, irrespective of the forms such re-enactment takes, is a tool for healing. It is the case, however, that without proper interrogation of the events, some texts risk offering no more than the ammeter poetry described by Gray as 'symptom not diagnosis. All that is registered, really, is the desperate resort to the familiar' (171). Such responses resist interrogation of existing social orders, of mourning and accepting change and acknowledging Western complicity and ongoing destruction overseas. Such texts seek only to locate the problem elsewhere, to return to how things were before the attacks.

Unlike the clinical psychologist who studies trauma at the individual level, Kaja Silverman focuses on the social effects of trauma. The ability of historical trauma to disrupt the 'natural' appearance of the dominant fiction and call into question the ideological beliefs that underpin it raises the possibility of two particular consequences. First, the loss of belief in the dominant fiction will result in it losing its ability to promote consensus and therefore a fragmentation of society may well occur. Second, marginalised ideologies may attempt to seize the opportunity presented to them by the destabilising effects of historical trauma to replace those ideologies that form the core of the dominant fiction. In this respect, historical trauma may potentially be seen as creative destruction in that it offers the opportunity for marginalised ideologies to assume positions of authority and attempt to fashion a new dominant fiction.

Gray contends that the scale of destruction and loss of life during the 9/11 terrorist attacks, whilst undeniably terrible, is incomparable in terms of scale to, for example, the Holocaust or the Vietnam War. According to Gray, 'crisis is as much a matter of perception, of feeling, as anything else. America had been impervious' (5), but after 9/11 “[ $t$ ]he homeland was no longer secure and, to that extent, no longer home" (Baer). The psychic impact of an attack on American soil shattered the sense of security held by many American (and indeed, Western) individuals. Many mainstream superhero comics reflected this sense of confusion, violation and dephallusization even if in doing so, as considered in the following sections, they reflect such sentiments only to cathartically resolve them.

The superhero genre is well acquainted with containing trauma. Superhero narratives are relatively dependent on scenes of spectacular disorder for their appeal. Superheroes 
necessarily require events of sufficient magnitude to justify the deployment of their superhuman abilities and these tend to manifest themselves as large scale threats to the social order. Wolf-Meyer contends that

[a]s agents of the law, the vast majority of superheroes are intent on retaining the status quo, subservient to the popular politics and will of the people they endeavor to protect. (501)

Post-9/11, however, trauma became ever more apparent, on some occasions even threatening to overwhelm the ongoing projects of order and stability central to superhero narratives (Wolf-Meyer 2003). This is most apparent in Amazing Spider-Man \#36 from November 2001 where rather than the 'stealth' approach, the 9/11 terrorist attacks literally occur in the comic-book, interrupting the flow of the existing narrative and exposing the helplessness of the tremendously powerful Spider-Man. If superheroes contribute to the mythology of US security then, when the myth of that security is shattered, superhero narratives must acknowledge that failing. As deputy editor of the Daily Bugle, Robbie Robertson, remarks, 'post 9-11 we're all trying to redefine our purpose.' This process of redefinition manifests itself in Disassembled through a complex means of acknowledging of historical trauma (Priest et al. 10). Demands on the superhero to restore order are counterbalanced by the inability of the superhero to ascertain how to do so and, as the narrative concludes, the willingness of superheroes to continue to engage with projects of order.

Representations of trauma are not limited to the attacks themselves. The Avengers: Finale from January 2005 opens with an image of the burning remains of the Avengers Mansion; these ruins bear a striking resemblance to coverage of Ground Zero and the remains of the World Trade Center. Such connections are borne out when Tony Stark, the financial sponsor of the Avengers, states that he has 'taken the liberty of starting the proper paperwork with the city of New York ... [to] declare this property a landmark ... I think it's a fitting memorial' (Bendis et al. Finale 10). The National September 11 Memorial Museum had begun construction 3 years before the publication of the arc, something that, like the remains of the Avengers Mansion, worked towards the creation of a commemorative space at the site of trauma. Even Finale, however, which seeks to fix mourning in geographical space and dictate its form, is haunted by fragmentation. Stark is no longer able to fund the Avengers, She-Hulk quits whilst Hank and Janet Pym, both founding Avengers, also announce their departure. The Falcon leaves the Avengers and contemplates retiring as a superhero altogether; Captain Britain returns to Britain, renouncing her role as an Avenger. What was once the premier superhero team in the Marvel universe has fragmented into a series of distinct individuals, something mediated through the fragmentary artistic style of the comic-book. Rather than one artist handling the entire comic-book, as is customary, Finale is drawn by at least 15 different artists, leading to a collision of different styles that works against viewing Finale as a coherent whole. Despite such strong messages of disunity, Finale ends with a demonstration of public support for the Avengers, although the large crowd that gather outside the wreckage of the Mansion recall images of crowds at Ground Zero. Fragmentation and unity therefore coexist and, to some extent, the unity can be seen to be at least partly caused by the fragmentation. Mass public support is scant consolation, however, for the scenes of devastation that precede it - it instead resembles an attempt to paper over cracks that have widened to chasms.

Mainstream superhero comics have, to an extent, acknowledged the ruptures made visible by $9 / 11$ by interrogating Western complicity in the attacks. Hawkeye, one of the Avengers, raises the question of whether the superheroes had brought the events of Disassembled on themselves: 
[W]e had it coming. This ain't going to be the most popular thing I ever say but, yeah, we had it coming. We're all about the short-term. We're all about whatever is in front of us that second and then we're onto the next thing. (Bendis et al. \#501 10)

Although ambiguous, the comment recalls claims that the US had to some extent been complicit in causing 9/11 through its short-sighted foreign policy over previous decades. Hawkeye's insight (in a rare moment which counters the common trends of the genre) therefore undercuts the use of reductive terms such as 'evil' and 'terrorist', in sharp contrast to the Manichean world view being promoted by President Bush through such statements as the definition of Iraq, Iran and North Korea as the 'Axis of Evil' (Bush 1). Hawkeye's nuanced approach cuts against the usual construction of superhero masculinity and morality - a sort of 'might makes right' that appears to be the only viable way of solving problems. It is the loss of ideological belief in this 'natural', unthinking masculine power as the means of ordering and protecting society that indicates the impact of historical trauma.

\section{Gender, National Identity and the Terrorist}

Having established the process of re-enactment and associated themes of helplessness and fragmentation in post-9/11 mainstream superhero comics, the remainder of this essay considers the ways in which heteronormative masculinity is rephallusized in the texts. Gray's use of the term 'impotence', in terms of the psychic damage of $9 / 11$ is appropriate. One crucial means of rephallusization is stressing the 'natural' connections between men and power. That such a project was necessary is borne out by the hysterical remarks of right-wing commentators such as Rev. Jerry Falwell who remarked of feminists and lesbians that 'I point the finger in their face and say, "you helped this happen", (Faludi 22). Falwell's (non-sensical) statement was met with outrage at the time, partly as a result of its similarity to pronouncements by Fundamentalist Muslims, but a similar casting of the attacks in terms of gender are visible in many mainstream superhero comics. These narratives, as we shall now consider, work to restore ideological belief in masculine ascendancy as part of a wider project of soliciting faith in the dominant fiction.

Avengers: Disassembled restages rather than re-enacts 9/11. Instead of purely drawing on contemporary traumatic imagery to lend its own narrative more weight, an accusation levelled at the series by Andy Schmidt who saw the presence of 9/11 resonances as an attempt to create an 'artificial impact', Disassembled engages with imagery of $9 / 11$ in order to bring about a specific result. The Avengers \#500 begins with an instance of badinage relatively typical of the superhero genre as Hawkeye and Ant-Man discuss the relative attractiveness of several female villains. Heteronormative masculinity is therefore established as dominant and normal at the beginning of the Disassembled arc. The tone at the conclusion of the arc, despite centring on a discussion of the Avengers' finest moments, is rather more downbeat. Although the majority of recalled moments are characterised by violence, each is also permeated with nostalgia, a desire that things could be as they once were. Avengers: Disassembled is therefore caught between the desire to go backwards and an inability to do so; trauma has disrupted continuity, causing massive devastation and calling into question many things previously accepted as natural. To further complicate matters, the serial nature of the form inexorably draws the superheroes forwards into an uncertain future robbed of the simplicity of the past, inherently destabilising superheroes and their ongoing projects of order. 
The destabilising effect of the 9/11 attacks on masculine power is evident in the casting of women in the role of aggressor through superhero re-enactments of 9/11. In Avengers: Disassembled, the villain behind the attacks on the Avenger's Mansion (described as a 'terrorist' [91 and 94]) is Wanda Maximoff. In an earlier narrative, Wanda had been happily married with two children. However, it transpired that these children were fictional and had to be destroyed to save the world; Wanda was then made to forget that she had ever had children. Wanda subsequently discovers that she has been deceived and the deception and loss of her children trigger mental instability. It is in this state that Wanda seeks to take revenge on those who had deprived her of her children. Foucault, amongst others, connects hysteria to the womb, nightmares and the feminine (130-7), which suggests, in this context, that Wanda (and by extension the terrorist) is beyond reason and that any attempt at understanding will meet the silent barrier of madness. The flashbacks and hallucinations that dominate Avengers: Disassembled (the characteristics of trauma) are accounted for through Wanda's ability to alter reality. They are, the narrative implies, not native to the male psyche, but imposed from without by an invading unknowable, feminine, horror. Such a position resists acknowledging the culpability mentioned by Hawkeye, or what Gray describes as 'our potential complicity: to turn the unspeakable into speech by acknowledging that it is men and women like ourselves who have committed acts that sometimes seem to terrible for words' (176). By feminising the enemy this narrative robs the terrorist of his or her phallic power. However, dangerous such an enemy may be, they lack the ability to phallically threaten heteronormative masculinity, or as Spiderman states 'girls can't control me - they can only contain me' (Spectacular Spider-Man \#16). Even in conflict, American identity encapsulated in the Superhero (Captain America is, Dittmer contends "a truth claim that defines America against a backdrop of otherness" [633]) can be defined against the female terrorist and reclaim phallic control.

The Avengers manage to restore order and, in terms of an evil being vanquished, the arc obeys the standards of the genre. The threat posed by Wanda is identified and contained and, despite their losses, the Avengers emerge as the victors - even if that victory is only represented indirectly through reflection on past achievements. To some extent, the mobilisation of past glories can be seen to engage with 'good war' rhetoric reminiscent of the Second World War, establishing a connection between the containment of fascism and the ongoing War on Terror through the pervasive $9 / 11$ that precede it.

Not all post-9/11 mainstream comics cast the terrorist as female. In the Captain America Enemy arc which followed 9/11, Captain America does battle with terrorists who invade a church (Rieber and Cassaday, 2002a,b). The lead villain of the arc is described by Dittmer as 'nameless, and of un-known ethnicity because of the burns over his face and therefore placeless' (640). Rather than being locatable in terms of geography and politics, the villain is a blank sheet onto which any geography or politics can be painted. All we know is that he is from outside the US. The terrorist, in Versluys' terms, is 'the ultimate Other' (17). The villain can represent any subject position which US national identity does not. The arc, Dittmer contends, 'set[s] up a clear dichotomy of insiders and outsiders, of innocent and unsuspecting domestic airline travelers [sic] and of distant, foreign intruders' (637). Rather than the psychoanalytical feminist approach discussed above, Dittmer reads the Captain America arc in terms of national (rather than gendered) identities, but with the same distinction between terrorist and victim; after 9/11 Captain America returned to his Second World War role with 'clear categories of good and evil, freedom and fascism' (637). 
What we do not encounter in Avengers: Disassembled, Captain America: Enemy or in any of the other post-9/11 superhero comics examined in this paper, is a terrorist in the literal sense of the hijackers who perpetrated the attacks, motivated by specific and identifiable cultural, economic and religious motives. The ultimate Other, by comparison, is necessarily unknowable and any attempt to realise him or her in fiction reflects, not the terrorist but those things from which the terrorist is constructed in the cultural imagination; everything which is unknowable. Whilst some poets and fiction authors have attempted, despite such barriers, to write the terrorist (if not sympathetically) empathetically, the approach in superhero comics has been largely to externalise the terrorist and to emphasise his or her Otherness. When we encounter the ultimate Other

it is impossible to deny that there are insurmountable differences. In some cases the Other insists on an otherness so complete that it refuses to be addressed and excludes all common ground.

The terrorists depicted are an amalgamation of various Others (the feminine and the foreign), of the things which provide a binary opposite to hegemonic male power. Depictions of the terrorist in these texts echo the sniper in Full Metal Jacket (1987), alien not only through language, geography and culture, but through gender as well. She is utterly unknowable.

\section{Recasting Masculine Hegemony}

As well as defining the terrorist as the ultimate Other, mainstream superhero comics, as discussed above, have had to address the fact that, quite simply, superheroes cannot protect the US. Not only the enemy, but the hero, must be redefined if the US is to be narratively rephallicized. The apparent failure on the part of superheroes is diverted in many mainstream superhero comics by endowing non-superheroes with superhero-like qualities. Such transformations are visible in the comic-book tribute volumes released to raise money for victims of the attacks and their families. In 'Unreal' from the second volume of 9-11 for instance, Superman narrates his physical capabilities whilst stopping a space shuttle from crashing into a satellite (Seagle et al. 15-7). In the subsequent panels, the audience see that the first page was metadiagetic; it is in a Superman comic held by a child who is being carried away from the burning World Trade Center in the reassuringly powerful arms of a fireman. Superman's narration continues

$[\mathrm{t}]$ he one thing I cannot do [...] is break free from the fictional pages where I live and breathe [...] become real during times of crisis [...] and right the wrongs of an unjust world. A world, fortunately, protected by heroes of its own. (16)

Here, rescue workers are described as, and endowed with the qualities and characteristics of, superheroes. It is important to note, however, that it is not the superheroes themselves who are capable of providing order; the sole point of continuity to which audiences can cling in this narrative is that firemen will save people. Whereas acts of heroism at Ground Zero were individual, they now take on a national resonance. 'Place your faith in men', this piece seems to say, 'they will rescue us from the chaos of these attacks and restore order'. Resonance here is not only national, it is also ideological; masculinity is represented as capable of redemptive action, something that reinforces ideologies of masculinity thrown into confusion through a loss of ideological belief in the dominant fiction precipitated by the terrorist attacks. 
Whilst self-described as non-fiction, stylistic conventions associated with the superhero genre are evoked in the 9-11 Report: A Graphic Adaptation to the point where such genre-distinctions are unclear. The debt to superhero style can be accounted for through the fact that the report was adapted by Ernie Colón Viking, who had previously worked on DC's superhero series The Green Lantern. Far more important than the reasons for the stylistic debt, however, are its effects. 9/11 is realised within the expectations of the superhero genre, both in visual and narrative terms. President Bush and other US politicians are therefore represented in the manner of superheroes, a project that contributes to the simplification of the attacks. Such constructions were not only limited to the pages of comic-books. For instance, Republican speechwriter Peggy Noonan felt it would not have been out of place for President Bush to reveal 'the big " $\mathrm{S}$ " on his chest' under his shirt in the manner of Superman (Faludi 47). Given the unswerving morality and physical capabilities of Superman, characterising the leader of the US as a superhero goes some way towards silencing dissent; few would argue with the ends of truth and justice but it would seem that no-one could argue with President Bush's interpretation of the 'American way'.

In the immediate aftermath of 9/11 this interpretation of the American way, according to Versluys, could be seen in 'the spontaneous expressions of sympathy [that] almost inevitably entailed the practice of pinpointing and then accusing the enemy,' a process that led to the creation of a sharp division between, as Bush remarked, those who were either 'with us' or 'with the terrorists' (150). To conclude on a point regarding Avengers: Disassembled, this series, perhaps unusually for conventional superhero narratives, resists the creation of simplistic binaries. Rather than being portrayed as a terrorist, as something radically unknowable in post-9/11 rhetoric, Wanda is ultimately recognised by the remaining Avengers as a former friend. The fact that Wanda is dangerous does not make her inhuman, nor does it Other her to the extent that she is ostracised from US society. Wanda's actions may destroy the Avengers but their fragmentation by no means indicates the end of the socio-political order they were sworn to defend or the removal of ideological belief from that order. In fact, the crowd that welcomes the departing Avengers indicates a desire for the continuation of values rather than the creation of new ones. Seen in this way, the dissolution of the Avengers does not have to stand for the end of anything; it is simply a reformulation, a redeployment of resources that, despite the refusal to distance itself from Wanda, can be seen as attempting to guarantee the continuation of existing values and relations of power. Rather than exploding established relations through the creation and entrenchment of new binaries, Avengers: Disassembled seeks to establish continuity - each of the individual Avengers will continue to act in the same way, it is just that the 'Avengers' as a unit is no longer fit for purpose. In fact, the Avengers would be replaced by the New Avengers almost immediately, a team united by the same principles and, in fact, consisting of almost the same characters. Trauma may disrupt the 'natural' appearance of normality but it cannot do so for long, with the (temporary) fragmentation of one particular superhero team proving incapable of truly disrupting existing relations of power. Threats may change but the means of resisting them enjoys an underlying continuity.

\section{Acknowledgement}

The authors wish to thank Owen Robinson and the two anonymous reviewers for their feedback and support. Philip Smith wishes to thank Brian Jarivis for his advice on an 
early draft of the paper and Robert Kraft for providing information which informed our models of trauma from the perspective of clinical psychology.

\section{Short Biographies}

Philip Smith is a PhD student with Loughborough University under the (excellent) tutelage of Dr Brian Jarvis. In addition to his studies, he is managing editor at Wiley-Blackwell.

Michael Goodrum's** research focuses on the relationship between traumatic events and representations of masculinity and heroism in popular culture; his work in these areas has appeared in Scan and US Studies Online. Current research utilises a psychoanalytic framework and a qualitative approach to examine the representation of women, race and popular protest in superhero comic-books of the 1960s and 1970s. Goodrum has taught at the University of Essex, where he completed both his $\mathrm{BA}$ in Philosophy and $\mathrm{PhD}$ in History, for the past 4 years; he also holds an MA in Literature from the University of East Anglia.

\footnotetext{
Notes

* Correspondence: Oxford Business Park North, Oxford, Oxfordshire OX4 2DQ, UK. Email: philip.smith@ wiley.com

** Correction added on 5 September 2011 after first publication on 17 August 2011. The first name of the second author, Michael Goodrum was erroneously spelled as 'Mitchel' on pages 487 and 497. The error has been corrected in this version of the article.

1 A crossover arc is a narrative that has an impact on every title in a publisher's universe. Although there was a Secret Invasion series, its events appeared in every Marvel title for the duration of the series.

2 Iron Man talks of 'terror' in The Avengers \#500, an ambassador from the fictional Wakanda discusses 'terrorists' with Captain America in Captain America and the Falcon \#5 (September 2004), Al Qaeda are mentioned in The Invincible Iron Man \#87 (October 2004) and when Wanda is first mentioned as a potential source for the attacks in The Avengers \#503 (December 2004), Iron Man states that the Avengers cannot accuse a team mate of 'this kind of terrorism'.
}

\section{Works Cited}

Baer, Ulrich. 110 Stories New York writes after September 11. New York: New York University Press, 2002.

Dittmer, Jason. 'Captain America's Empire: Reflections on Identity, Popular Culture, and Post-9/11 Geopolitics.' Annals of the Association of American Geographers 95.3 (2005): 626-43.

Faludi, Susan. The Terror Dream: What 9/11 Revealed About America. London: Atlantic Books, 2008.

Foucault, Michel. Madness and Civilisation. London: Routledge Classics, 2001.

Goleman, Daniel. Emotional Intelligence: Why it can matter more than IQ. London: Bloomsbury, 1995.

Gray, Richard. After the Fall. Malden: Wiley-Blackwell, 2011.

Laub, Dori. 'September 11, 2001 - An Event without a Voice.' Trauma at Home: After 9/11. Ed. Judith Greenberg. Lincoln: University of Nebraska Press, 2003. 204-15.

Neal, Arthur G. National Trauma and Collective Memory: Extraordinary Events in the American Experience. Armonk: M.E. Sharpe, 2005.

Silverman, Kaja. Male Subjectivity at the Margins. London: Routledge, 1992.

Versluys, Kristiaan. Out of the Blue. Columbia: Columbia University, 2009.

Weber, Cynthia. Faking It: U.S. Hegemony in a 'Post-Phallic' era. Minnesota: University of Minnesota Press, 1999.

Wolf-Meyer, Matthew. 'The World Ozymandias Made: Utopias in the Superhero Comic, Subculture and the Conservation of Difference.' Journal of Popular Culture 36.3 (2003): 497-517.

\section{EMAIL CORRESPONDENCE}

Kraft, Robert N. Email correspondence (Smith) 30/09/09. 


\section{COMIC-BOOKS}

Avon Oeming, Michael and Andrea DiVito. The Mighty Thor. New York: Marvel, 2004.

Bendis, Brian, Dave Finch, et al. The Avengers \#500: Director's Cut. New York: Marvel, 2004.

,-- , et al. The Avengers \#501. New York: Marvel, 2004.

- - - et al. The Avengers \#502. New York: Marvel, 2004.

- - e et al. The Avengers \#504. New York: Marvel, 2005.

Jacobsen, Sid and Ernie Colón Viking. The 9/11 Report: A Graphic Adaptation. New York: Hill \& Wang, 2006.

Priest, Christopher, Joe Bennett, et al. Captain America and the Falcon \#5. New York: Marvel, 2004.

Rieber, J. N. and J. Cassaday. Enemy Chapter One: Dust from Captain America, no. 1, 1-37. New York: Marvel Comics, 2002a.

and - Enemy Chapter Two: One Nation from Captain America, no. 2, 1-23. New York: Marvel Comics, $2002 b$.

Various authors. 9-11 The World's Finest Comic Book Writers and Artists Tell Stories to Remember. New York: DC, 2002.

\section{WEBOGRAPHY}

Bush, George. 'State of the Union Address.' Retrieved on 10 September 2010 from: http://archives.cnn.com/ 2002/ALLPOLITICS/01/29/bush.speech.txt/.

Krupa, Charles. 'Day of Infamy.' Time 12 September 2001. Retrieved on 29 July 2010 from: http://www.time. com/time/nation/article/0,8599,174502,00.html. 